\title{
Directions for Solving Bad Workman Practices in Power Distribution Line Connections
}

\author{
A.G.D.P. Jayasekara, J. R. Lucas and W.D. A. S. Wijayapala
}

\begin{abstract}
Standardization of the process of power line connector installation and proper die selection technique for compression connectors is essential for power system reliability improvements. This paper presents an attempt to identify good workman practices required for making proper power distribution line connections. This will be a guide in the assembly and preventive maintenance of efficient electrical connections for power distribution circuits. Data and experience gained through usage of power line connectors by Ceylon Electricity Board is the basis of this study. Properties of conductor metals and metal oxides illustrate the requirements of standardized methods of making connections. Requirements for the proper selection of connectors; the proper preparation of conductors; and the proper application of fusion, compression, and bolted connectors are identified. Standards available on power line connectors are given. Photographs of bad workman practices are included with explanations. Mathematical formulas are developed for calculating the correct die size for compression connectors. Performance identification of any type of connector installed in a power line is carried out by thermal imaging. Thermal images taken from a few installed connectors are included and a procedure for assessing connector performance is suggested.
\end{abstract}

Keywords: Connectors, workman practices, die selection

\section{Introduction}

Power generated in remote stations is brought to load centers via the transmission network. The voltage is then stepped down at the grid substations for distribution to the local area. Each grid substation supplies its local area through several distribution feeders.

The intended purpose of this paper is to provide the user with the information necessary to make a decision on the selection of the correct connection method and procedure of making a connection in the power distribution system. This paper introduces various electrical connection points in the power distribution network where different types of connectors can be applied and their related conditions to consider when selecting and working with connectors. This research mainly focuses on providing a technical background for facilitating sound judgment when applying an appropriate way of connection suitable for a particular point in the power distribution network.

\section{Fusion and pressure connections}

Fusion and pressure connections are the two main types of connections in practice for making power line connections. Fusion refers to joining conductors by melting of parent metals, or a third metal. Welding, Soldering and Brazing can be identified as main types of fusion connections. A properly made welded or soldered joint is a good joint but the quality is more depend on the skill of the person. Requirements of high temperature or sophisticated equipments for different forms of welding such as arc welding, laser welding, friction welding, spot welding, etc decreases the convenience and the economy in the field of making electrical connections. Soldering or welding may weaken the conductor by annealing and heat may damage the cable insulation reducing the reliability of the electrical connection.

Physical contact made between coincident peaks on the surface of the conductor and the connectors by applying a suitable pressure are identified as pressure connections.

Eng. A.G.D.P. Jayasekara, BScEng(Hons), MSc(Moatuwa), AIE(Sri Lanka),Planning Engineer, Western Province North, Ceylon Electricity Board, Sri Lanka.

Prof. J. R. Lucas, BScEng(Ceylon), MSc(Manch), PhD(Manch), FIEE, CEng, FIE(Sri Lanka), IPEng, MCS(SLanka), Senior Professor, Department of Electrical Engineering ,University of Moratuwa, Sri Lanka.

Eng. W.D. A. S. Wijayapala, BScEng(Hons), MEng, IPEng, CEng, FIE(Sri Lanka), Senior Lecturer, Department of Electrical Engineering, University of Moratuwa Sri Lanka. 
Appropriate pressure should be applied, in order to make the contact and conducting area to be adequate. The peaks present on metal surfaces are deformed when applying the pressure, resulting in higher contact area. Compression-type connectors and clamp-type connectors are the two main types of pressure connectors used in the field of making electrical connections.

Good performance from the joints and terminations is necessary for the reliable operation of the power system.

\section{Area of contact}

Two metal surfaces are placed together for making electrical contact. However, metal surfaces are not smooth. Therefore, a limited number of points (peaks) on one surface only contacts with the other surface. The actual contact area will be small compared to the total.

The area of contact refers to this concept. A microscopic view of the extruded metal surface is shown in Figure 1. It is seen to be not uniform due to the presence of peaks and dips. The red coloured area represents the peaks and the dips can be identified by the blue coloured area. However, it must be noted that, these measurements are in micro meter level.

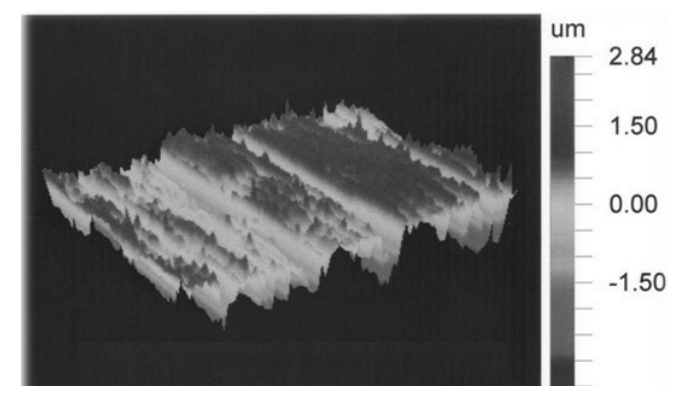

Figure 1- Extruded metal surface (approx. $1 \mathrm{~mm} \times 0.7 \mathrm{~mm}$ ) [1]

The fractional area of True Mechanical Contact is estimated as $7 \%$ of total area. The "electrical contact" area may sometimes be as small as 0.1 percent of the nominal contact area due to the presence of surface contaminated layers [1].

\section{Material properties, effective connection methods and procedures}

Copper and aluminium are the two most commonly used materials for conductors and connectors in power systems. Silver is generally considered as the best electrical conductor. However its high cost and low strength limit its use to special applications such as plating of sliding contact surfaces.

\subsection{Aluminum oxide}

Mechanism: $2 \mathrm{Al}+3 /{ }_{2} \mathrm{O}_{2} \rightarrow \mathrm{Al}_{2} \mathrm{O}_{3}$

Aluminium oxide is tough, very hard, invisible, waterproof, high resistance and protective in nature. It has good corrosion resistance except in salty atmosphere. It forms quickly on exposed aluminum and the oxide prevents further oxidation once stabilized. Oxides must be broken or removed before making up connections. The film is so transparent that the bright and clean appearance of an aluminum conductor is no assurance of a good contact. After cleaning the oxide film from aluminum, a compound must immediately be applied to prevent the oxide from reforming.

\subsection{Galvanic action on Aluminium}

When aluminum is placed with any other metal (e.g., copper or steel) in an electrolyte (e.g., water), galvanic corrosion occurs proportional to the distance between them in the electrolyte series. This difference causes a flow of electrons, pitting the aluminum but keeping the other cathodic material unharmed.

\subsection{Copper oxide}

Mechanism: $\mathrm{Cu}+\mathrm{O} \rightarrow \mathrm{CuO}$

Copper oxide is formed immediately when copper is exposed to the atmosphere. At temperatures above $88{ }^{\circ} \mathrm{C}$, copper oxidizes in dry air[1]. It is non-conductive and a discoloration from the base metal (dark green or black) can be observed. Copper oxide is generally broken down by reasonably low values of contact pressure compared with aluminum. Unless the copper is very badly oxidized, good contact can be obtained with minimum cleaning. It is a good practice to silver-plate copper contact surfaces that must be operated at elevated temperatures, because the silver oxide is easily broken down by contact pressure and forms less readily at elevated temperature.

\subsection{Expansion of metals}

Aluminum, copper, and steel have very much different coefficients of expansion. Connectors may expand in the day time and may contract at night. This phenomenon can also occur during peak and off peak load conditions. Copper compression connectors should not be used for aluminum conductors. Proper torque 
and washers should be used in installation of bolted connectors.

\subsection{Corrosion of connections in power circuits}

Corrosion is caused by the electrolytic action of moisture and other elements of the atmosphere in conjunction with the metals of the connection. Corrosion is a minor factor in copper connections. However, it is a vital factor if aluminum is involved, unless moisture can be kept away from the connection $[1,2]$.

\subsubsection{Galvanic action}

Whenever dissimilar metals are present in an electrolyte, an electric potential is developed: One metal becomes the cathode and receives positive charges while the other becomes the anode and receives negative charges. When these metals are in contact, an electric current will flow, and this electrolytic action causes an attack on the anodic (negatively charged) metal leaving the cathodic (positively charge) metal unharmed.

\subsubsection{Crevice corrosion}

Corrosion can occur due to the presence of the electrolyte in similar metals by a phenomenon known as oxygen concentration cell or crevice corrosion [3]. Oxygen is necessary for corrosive action. Variation in the concentration of oxygen, where a metal is exposed to an electrolyte will generate an electrical potential and cause a corrosive attack in the oxygen starved area. The Fontana and Greene model describes the crevice corrosion mechanism [3].

\subsubsection{Corrosion prevention techniques}

Applying joint compounds and plating are usually used for oxidation prevention.

\subsubsection{Applying joint compounds}

Joint compounds prevent formation of oxides on cleaned metal surfaces and also prevent moisture entering the connection. Compounds fill any crevices present in the connection thus reducing the chances of crevice corrosion. Petroleum based compound with higher melting point, higher oxidation resistance and better weathering characteristics are used as a joint compound [4]. One type of compound includes a chemical which penetrates the oxide film by chemical action. This is recommended for aluminum to aluminum bolted connections. Another type consists of a suspension of zinc granules. This can even be used with aluminium to copper joints. The zinc granules tend to enter into the contact surface, penetrating the oxide coating and providing additional current paths between contact surfaces. Furthermore, the joint compound comes out during compression and is responsible for taking the oxides out.

\subsubsection{Plating of contact surfaces}

Care must be taken not to plate the anode when two metals are in contact. Because, any damage point in the plating will increase the current density at that point resulting in a severe attack.

\subsection{Anodizing of aluminum.}

Aluminium is anodized to increase corrosion resistance and surface hardness. This is done primarily for bolts. This is an electrolytic process. When exposed to air at room temperature, pure aluminium forms a surface layer of amorphous aluminium oxide of 2 to $3 \mathrm{~nm}$ thick [5]. Aluminium alloy parts are anodized to increase the thickness of this layer for corrosion resistance.

\subsection{Selection of connectors}

The corrosion and thermal effects should be considered in the selection of connectors. Galvanic corrosion can be prevented by using the same metal wherever possible.

\subsubsection{Aluminium to aluminium connections} A connector with an aluminium body will be the proper choice for joining aluminum to aluminum conductors, since the galvanic corrosion and thermal effect will be eliminated. Aluminium alloy can also be recommended since the galvanic and thermal properties are not much different from pure aluminium. However, the connector must be free from cracks to avoid crevice corrosion.

\subsubsection{Copper to copper connection}

For joining copper conductors, the connector must also be copper.

\subsubsection{Aluminum to copper connections}

Even for aluminium to copper conductor joints, an aluminium bodied connector is recommended. However, the mass of aluminium should be considerably higher than copper to prevent galvanic corrosion. This is known as the massive anode principle.

\subsubsection{Massive anode principle}

The electrolytic current density over the exposed face of the aluminum connector is greatly reduced by making the aluminum connector massive in comparison to the copper conductor. The rate of corrosion is directly 
related to the current density on the surface of the anodic material. Therefore, the damage caused to the aluminium connector is minor. Furthermore, this small loss of aluminium is negligible when compared with the size of the aluminium connector even for a longer period. The aluminium connectors designed to join aluminium and copper conductors should keep an adequate separation between conductors. This is to prevent the deterioration of the aluminium conductor due to electrolyte attack. Furthermore, it is a good practice to keep the aluminium conductor physically above the copper conductor to prevent dropping of copper ions to the aluminium conductor.

\subsubsection{Bolted connections}

For bolted connections, the bolt should be compatible with the connector. Nuts and flat washers should be of the same material as the bolt. Zinc or cadmium plated or stainless steel bolts are also recommended for bolting aluminum or aluminum to copper.

\section{Standards}

Different British standards, German standards and Indian standards related to power line connections discuss selection of connectors and effective workman practices [6-10].

\section{* ANSI C119.4-2003: American National Standard for Electric Connectors- Connectors for use between Aluminium to Aluminium or Aluminium to Copper bare overhead conductors [6].}

This standard establishes a testing procedure to ascertain the performance of connectors to be used between aluminium-to-aluminium or aluminium-to-copper bare overhead conductors. Tests to be done for both electrical and mechanical performance of the connector are formulated. Current Cycle Test (CCT) and the Current Cycle Submersion Test (CCST) are the two methods have been adopted for testing the electrical performance. Electrical performance testing is based on testing of the stability of the connector temperature and the connector resistance in various current cycles to be performed according to the different connector classes. However, this standard cannot be used for testing a specific connector which is already installed, since testings should be done in a laboratory. This standard doesn't include guidelines for installing connectors. The standard BS 7609-1992 provides instructions to be followed for the installation of uninsulated compression and mechanical connectors.
* BS 7609-1992: Code of Practice for Installation and inspection un-insulated compression and mechanical connectors for power cables with copper or aluminium conductors [7].

Guidelines provided by the standard are directly applicable to the transformer tail wire connection. This standard recommends methods and procedures for selection of connectors, preparation of conductors and connector installations. Procedure for inspection of the completed compression connection is given for ensuring the effective connection. BS 7609:1992 illustrates examples of unsuccessful workman practices for power line connections by figures for easy identification. Section 5 of BS 7609:1992 is about mechanical connectors. Procedure for installing and inspection of mechanical connectors is provided. Torque wrench settings are recommended for aluminium and copper terminations. The standard directs on maintenance, testing and certification of mechanical, hydraulic and pneumatic compression tools. Certification of all tooling should be done before providing those into service and periodic re-certification is to be done. Information to be included in the test certificate is given in clause A.9 of BS 7609:1992. Following two German standards provide dimensions for aluminium and copper cable terminations respectively. Identification of correct dimensions for different sizes of connectors is essential for selection of suitable connectors.

* DIN 46 329-1983: German Standard-Cable lugs for compression connections, Ring type for aluminum conductors [8].

* DIN 46 235-1983: German Standard-Cable lugs for compression connections, Cover plate type for copper conductors [9].

\section{Connectors for power distribution system}

The power distribution system maintained by Ceylon Electricity Board, Sri Lanka is taken into consideration. Conductors used for medium voltage and low voltage power distribution in CEB are given in the table 1.

Connectors suitable for following different connections in power distribution system are identified. 

a) Jumper connections for bare conductors.
b) Tension joints for bare conductors. c) Connections for Arial Bundled
Conductors.
d) Service wire joints.
e) Energy meter terminal connection.
f) Transformers flag connection.
g) Earth connections.

\subsection{Connectors for Jumper connections of bare conductors}

Connectors used in jumper connections are not under tension. Tapping of conductors are also done at jumper points with non-tension connections. Different sizes of ' $\mathrm{H}$ type connectors' are recommended for jumper connections. Figure 2 shows an $\mathrm{H}$ type connector. It has two grooves for inserting conductors at jumper points. A non-tension joint should have at least $25 \%$ of tensile strength of the conductor [6].
Conductor preparation should be done before inserting conductors to the connector. A Tension joint must possess at least $95 \%$ of the conductor tensile strength [6]. There are different sizes of sleeves available for the same conductor according to sleeve material and its usage. Sleeves are used for short span pole lines as well as tower lines. Tower lines have higher conductor spans compared to pole lines. Different sleeve dimensions can be observed in American, European or Eastern practices. Sleeve must be compressed with correct size of die in order to make an effective connection. Sleeves are compressed from middle to ends usually as air would be trapped inside, if the crimped from end to middle, resulting high pressure inside. However, "Anti bird-caging sleeves" are designed to be crimped from the outer position first. This type of sleeve has pressure relief holes located at the centre of the

Table 1- Conductors used for MV and LV power distribution in CEB

\begin{tabular}{|c|c|c|c|c|c|c|}
\hline \multirow{2}{*}{\multicolumn{2}{|c|}{ Conductor }} & \multicolumn{2}{|l|}{ Size } & \multicolumn{3}{|c|}{ Cross sectional Area $/ \mathrm{mm}^{2}$} \\
\hline & & \multirow{2}{*}{$\begin{array}{l}\mathrm{mm} \\
7 / 1.35\end{array}$} & \multirow[t]{2}{*}{ Inches } & \multirow{2}{*}{$\begin{array}{l}\text { Al- } \\
\text { Nominal } \\
10\end{array}$} & \multirow{2}{*}{$\begin{array}{l}\text { Total } \\
10.02 \\
\end{array}$} & \multirow[t]{2}{*}{$\begin{array}{l}\text { AWG } \\
\text { (Approximate) }\end{array}$} \\
\hline \multirow{2}{*}{$\begin{array}{l}\text { Service } \\
\text { Connection }\end{array}$} & $30 \mathrm{~A}$ & & & & & \\
\hline & $60 \mathrm{~A}$ & $7 / 1.70$ & & 16 & 15.89 & \\
\hline \multirow{2}{*}{ LV } & Fly & $7 / 3.40$ & $7 / 0.134$ & 60 & 63.55 & $2 / 0$ \\
\hline & Wasp & $7 / 4.39$ & $7 / 0.173$ & 100 & 105.95 & $4 / 0$ \\
\hline \multirow{4}{*}{ MV } & Weasel & $6 / 1 / 2.59$ & $6 / 1 / 0.102$ & 30 & 36.90 & $\# 2$ \\
\hline & Raccoon & $6 / 1 / 4.09$ & $6 / 1 / 0.161$ & 75 & 91.95 & $3 / 0$ \\
\hline & Lynx & $30 / 7 / 2.79$ & & 175 & 226.20 & $397.5 \mathrm{kcmil}$ \\
\hline & Elm & $19 / 2.59$ & & 175 & 211 & $397.5 \mathrm{kcmil}$ \\
\hline
\end{tabular}

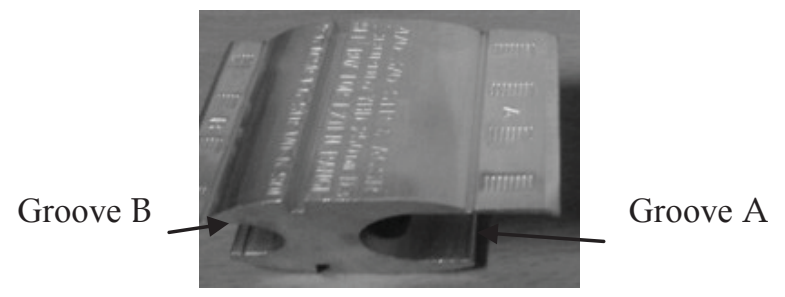

Figure 2- $\mathrm{H}$ type connector

\subsection{Tension Joints for bare conductors}

Tension joints are used, if the conductor end comes to a point in-between two shackle poles while stringing or when a conductor is broken. Compression sleeves are recommended for tension joints of bare conductors. Figure 3 shows a compression connector.

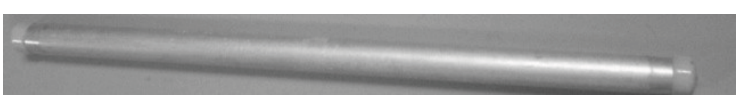

Figure 3- A compression connector sleeve to allow the oxide inhibitor and air to bleed out as crimping takes place.

Bird-caging refers to the separation of cable conductor strands at the entrance of a sleeve after crimping. This happens due to different expansions of sleeve and conductor during compression.

'Bowing' or 'Bananaing' is another term associated with compression sleeves. Bowing refers to the curvature that can occur on a completed compression connection. Bowing is sometimes caused by the natural curvature of the cable conductor (caused by storage on a reel). To avoid this, first, the cable conductor should be straightened as much as possible before being inserted into the connector sleeve. Secondly, the operator can carefully apply force by hand opposite to the bow direction to straighten the sleeve. 


\section{3}

\section{Connections for Arial Bundled Conductors}

Arial Bundled conductors (ABC) are used in LV power distribution. These have many advantages compared with bare conductors, since these are insulated conductors. Four core $A B C$ consist of 3 phases and neutral. Street lamp line is added to make five core $\mathrm{ABC}$ cable. Neutral is alloy and it takes the tension. Figure 4 shows a cross sectional view of five core $\mathrm{ABC}$.

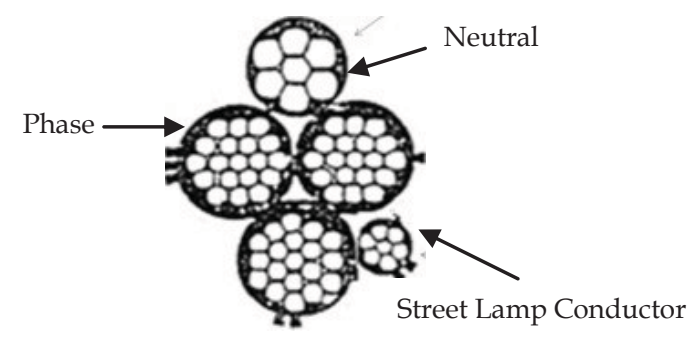

Figure 4 - Cross section of LV Aerial Bundled Conductor

Standard colour code is set for easy identification of connectors for conductors of the bundle cable. Usually the protective cap which is fixed to prevent spoilage and spillage of compound inside a lug or a sleeve is colored according to this standard.

\section{* Phase conductors $\left(70 \mathrm{~mm}^{2}\right)$ - White \\ - Neutral conductor $\left(54.6 \mathrm{~mm}^{2}\right)$ - Black \\ - Street Lamp conductor $\left(16 \mathrm{~mm}^{2}\right)$-Blue}

Sleeves given in figure 5 are used for joining conductors while stringing or in case of a broken conductor. Green colored $\left(10 \mathrm{~mm}^{2}\right)$ sleeve is not used for $A B C$, but can be used for joining $10 \mathrm{~mm}^{2}$ service wires.

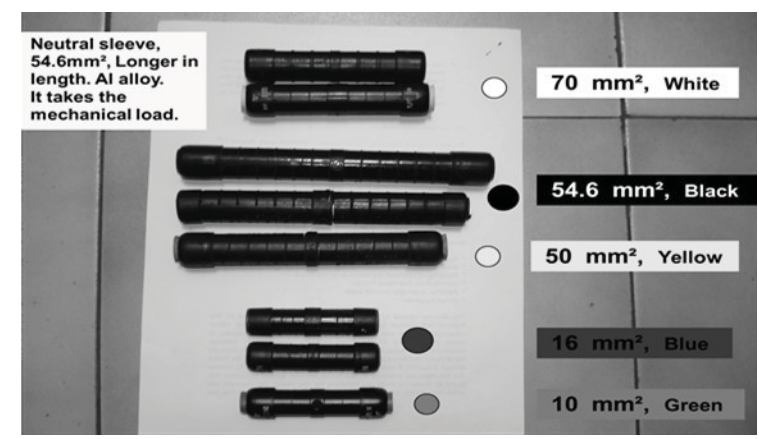

Figure 5 - Sleeves for bundle conductor with color code

Insulated lugs are available for connecting $\mathrm{ABC}$ to equipment terminals. The Conductor should be wire brushed thoroughly before inserting. The cable should be inserted to the connector without removing the end cap for water tied joints.

\subsection{Substation LV feeder connection}

The tail wire from the transformer LV flag is an insulated copper wire. This should be connected to AAC (All Aluminium Conductors) of low voltage feeders. Therefore, a connector suitable for aluminium to copper connection should be used. An aluminium bodied connector is suitable for this. Line taps with adjustable spacers or 'E clamps' are shown in figure 6 are recommended. The shape of the 'E clamp' provides an additional advantage for easy hanging of tail wire for installation. Furthermore, the aluminium quantity is higher to be suitable for massive anode action.

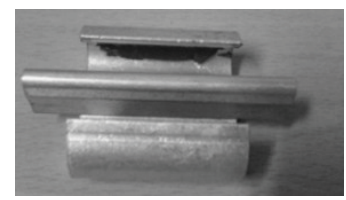

Figure 6 - E clamps for substation LV feeder connection

6.5 Service wire joints

CEB uses two sizes of duplex service wires (All Aluminium conductors) $10 \mathrm{~mm}^{2}$ $(7 / 1.34 \mathrm{~mm})$ and $16 \mathrm{~mm}^{2}(7 / 1.73 \mathrm{~mm})$ for $30 \mathrm{~A}$ and $60 \mathrm{~A}$ connections respectively. Insulated connectors are recommended for joints in service wires.

\subsection{Energy meter terminal connection}

Meter terminal is copper and service wire is aluminium. Therefore, galvanic corrosion will cause the resistance of the connection to increase. Increase of temperature will damage the meter terminal. Hence a bimetallic connector shown in figure 7 is recommended. Aluminium service wire is inserted to the barrel of the connector and the copper pin is inserted to the energy meter terminal. Use of the same metal avoids galvanic corrosion.

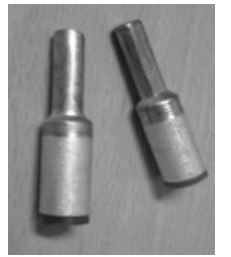

Figure 7- Bimetallic pin connector for energy meter terminal

\subsection{Exothermic Welding}

Welded joints are recommended for ground level connections, since the connection is affected more by bad environmental conditions compared to overhead connections [11]. The copper clad steel earth rod is connected to the down copper conductor in substation by exothermic welding. The process uses finely 
divided metallic aluminum as the reducing agent with copper oxide to cause molten copper to flow into a mold containing the conductors. The exothermic reaction is given below.

$$
2 \mathrm{Al}+3 \mathrm{CuO} \rightarrow 3 \mathrm{Cu}+\mathrm{Al}_{2} \mathrm{O}_{3}
$$

This reaction generates super heat of $4000{ }^{\circ} \mathrm{F}$ $\left(2200^{\circ} \mathrm{C}\right)$. The exothermic welding material has a very high copper content. It will be more than $90 \%$. Therefore, the exothermic welded joint has a cross section of more than twice the conductor.

\section{Die selection}

Different compression connectors are used in the power distribution system. Dies are required to compress connectors. The Correct die for each and every compression connector is required. Circumferential dies and hexagonal dies are available for compression connectors. A hexagonal die is shown in figure 8 . Hexagonal dies are the common type available. They are identified by the 'Across flat dimension'. Across flat dimension of a die is defined as the distance between two faces of the hexagon.

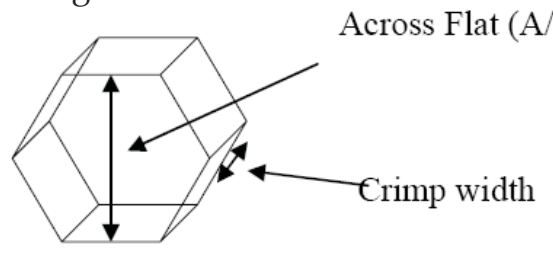

Figure 8- Hexagonal die

The number of compressions required to be done to crimp a connector is decided by the width of the die. The circumferential die is identified by the die number provided by the manufacturer. It is very important to identify the correct die for the connector. Otherwise, the connection will fail. An alternative die for a connector can be selected if a correct die selection method is known. The die selection method formulated is based on matching of metallic areas of the connector, conductor and the die.

The conductor is inserted to the connector before compression. The total cross sectional area of the connector and the conductor is calculated by the equation (4). A conductor with seven numbers of strands is considered.

$$
\frac{\pi}{4}\left(D^{2}-d^{2}\right)+7 x \frac{\pi d^{\prime 2}}{4}
$$
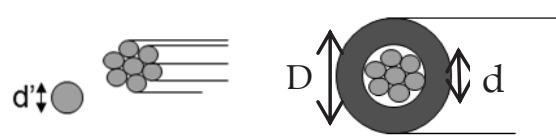

Where;

D - Outer diameter of the connector

$\mathrm{d}$ - Inner diameter of the connector

$\mathrm{d}^{\prime}$ - Diameter of a strand

Figure 9 - Total cross sectional area of the connector and conductor

Across flat dimension of the die should be selected such that the area of the die is $5 \%$ to $15 \%$ less than the total area of connector and the conductor to fill gaps in between the conductor strands and the connector and for cold flow of material.

Across flat dimension of the correct die can be calculated by the equation (5) for hexagonal die. For $10 \%$ cold flow deformation (for hexagonal die);

$\left(\frac{\pi}{4}\left(D^{2}-d^{2}\right)+7 x \frac{\pi d^{\prime 2}}{4}\right)=1.1\left(\frac{3}{8} \sqrt{3} D_{1}^{2}\right)$

Where; D1 is the corner to corner distance of the hexagonal die.

In this case, it must be ensured to use the correct conductor. It should be verified whether the suggested hexagon is inside the sleeve.

So, check..... $\mathrm{D}_{1} \approx \mathrm{D}$ or

Multiply the outer diameter of the sleeve by 0.866 to get the A/F of hexagon inside.

If the die is of the circumferential type as shown in figure 10, the area of the die is calculated as follows.

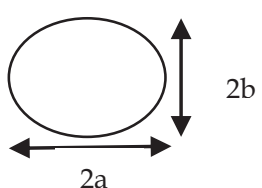

Figure 10 - Cross section of circumferential die

Area of the die $=\Pi \times a \times b$

The table 2 shows calculated die sizes for typical sizes of connectors used in power distribution system of CEB. The difference of areas between the conductor plus connector cross section and die selected is given in last column of table 2. Correct die can be selected by observing this figure.

This is represented in the figure 9. 
Table 2- calculated die sizes for typical sizes of connectors used in CEB

\begin{tabular}{|c|c|c|c|c|c|c|c|c|c|c|}
\hline \multirow{2}{*}{ है } & \multicolumn{3}{|c|}{ Connector data } & \multirow{2}{*}{ 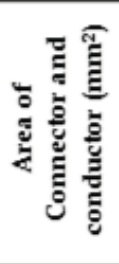 } & \multicolumn{2}{|c|}{ Suggested Die } & \multicolumn{2}{|c|}{$\begin{array}{c}\text { Area of the } \\
\operatorname{Die}\left(\mathrm{mm}^{2}\right)\end{array}$} & \multicolumn{2}{|c|}{$\begin{array}{c}\text { Area } \\
\text { difference as } \\
\% \text { of total }\end{array}$} \\
\hline & $\begin{array}{l}\mathrm{OD} \\
(\mathrm{mm})\end{array}$ & $\underset{(\mathbf{m m})}{\mathrm{ID}}$ & $\begin{array}{c}\text { Area } \\
\left(\mathrm{mm}^{2}\right)\end{array}$ & & 总 & 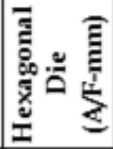 & 总 & 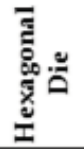 & 总 & 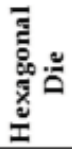 \\
\hline Fly & 20.5 & 11.3 & 229.9 & 293.4 & W660 & 17.3 & 263.1 & 259.2 & 10.3 & 11.7 \\
\hline \multirow{2}{*}{ Raccoon } & 25.3 & 13.7 & 355.5 & 447.4 & & 21.5 & & 400.3 & & 10.5 \\
\hline & 23.2 & 13.7 & 275.4 & 367.4 & U658 & & 329.4 & & 10.3 & \\
\hline \multirow{3}{*}{ Weasel } & 16.7 & 9.4 & 149.7 & 186.6 & W245 & 14 & 168.9 & 169.7 & 9.5 & 9.0 \\
\hline & 16 & 8.2 & 148.3 & 185.2 & W245 & 14 & 168.9 & 169.7 & 8.9 & 8.4 \\
\hline & 14.6 & 9.1 & 102.4 & 139.3 & W243 & 12 & 129.2 & 124.7 & 7.2 & 10.5 \\
\hline \multirow{3}{*}{ Lynx } & 38.1 & 23.2 & 717.6 & 943.8 & & 32 & & 886.8 & & 6.0 \\
\hline & 32.7 & 20.2 & 519.6 & 745.8 & & 27.5 & & 654.9 & & 12.2 \\
\hline & 32.9 & 21.2 & 497.3 & 723.5 & & 27.5 & & 654.9 & & 9.5 \\
\hline ELM & 30 & 19.9 & 395.9 & 606.9 & & 25 & & 541.3 & & 10.8 \\
\hline Lug-Weasel & 14.4 & 8.7 & 103.3 & 140.2 & W243 & 12 & 129.3 & 124.7 & 7.8 & 11.1 \\
\hline Lug-Weasel & 16 & 8.2 & 148.3 & 185.2 & W245 & 14 & 168.9 & 169.7 & 8.8 & 8.4 \\
\hline Lug-Fly & 20.5 & 11.3 & 229.9 & 293.4 & W660 & 17.3 & 263.1 & 259.2 & 10.3 & 11.7 \\
\hline Lug-Raccoon & 20.5 & 13 & 197.4 & 289.4 & W660 & 17.3 & 263.1 & 259.2 & 9.1 & 10.4 \\
\hline
\end{tabular}

\section{Theory of compression connectors}

Cold flow deformation could be obtained on a connector compression by exceeding the elastic limit of the metal. If connectors are not compressed up to the elastic limit (i.e. only in the elastic region), it will not maintain the contact between the conductor and connector properly.

The compression width of the die should be selected depending on the connector size and the material. Material could be aluminum, copper alloy or steel. Elastic limits of these materials are different. Increase of die width will result to compress more metal area in one compression. However, for same across flat dimensional die, steel compression die is smaller in width to the copper and that of copper is smaller to the aluminium. This is because, steel has higher elastic limit compared to copper or aluminium. Pure aluminium has elastic limit of $34500 \mathrm{kPa}$ [12]. $22 \mathrm{kN}$ force is required to compress one squire inch of pure aluminium to its elastic limit. Compression tools are available with compression forces of $5 \mathrm{kN}, 120 \mathrm{kN}, 500 \mathrm{kN}$, etc.

The calculation of effective die width according to the material and connector size is shown below. Figure 11 shows the cross section of a hexagonal die and Figure 12 shows the side view of a hexagonal die.
$\mathrm{F}=$ Force applied by the tool

$\mathrm{E}=$ Elastic limit of the material

$X=$ across flat dimension of the die

$\mathrm{W}=$ width of the die

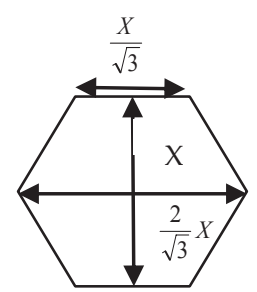

Figure 11 - Cross section of hexagonal die

Corner to corner distance; $\frac{2}{\sqrt{3}} X$

Length of one side of hexagon; $\frac{X}{\sqrt{3}}$

Cross sectional area covered by one compression;

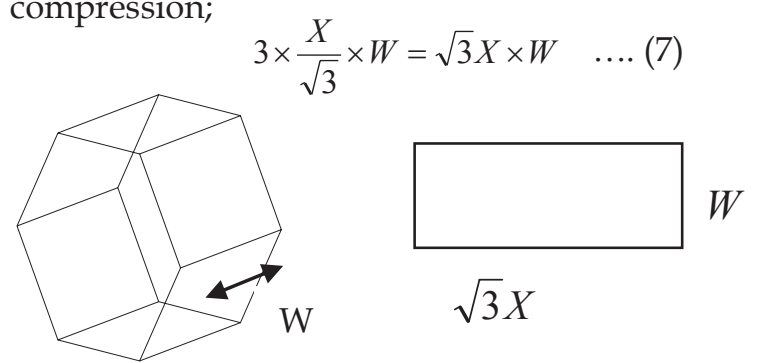

Figure 12- Side view of hexagonal die

Then, Area of the die which can be used to compress material up to its elastic limit is F/E.

Width of the die $=\frac{F}{E \times \sqrt{3} X}$ 


\section{Unsuccessful workman practices in electrical connections}

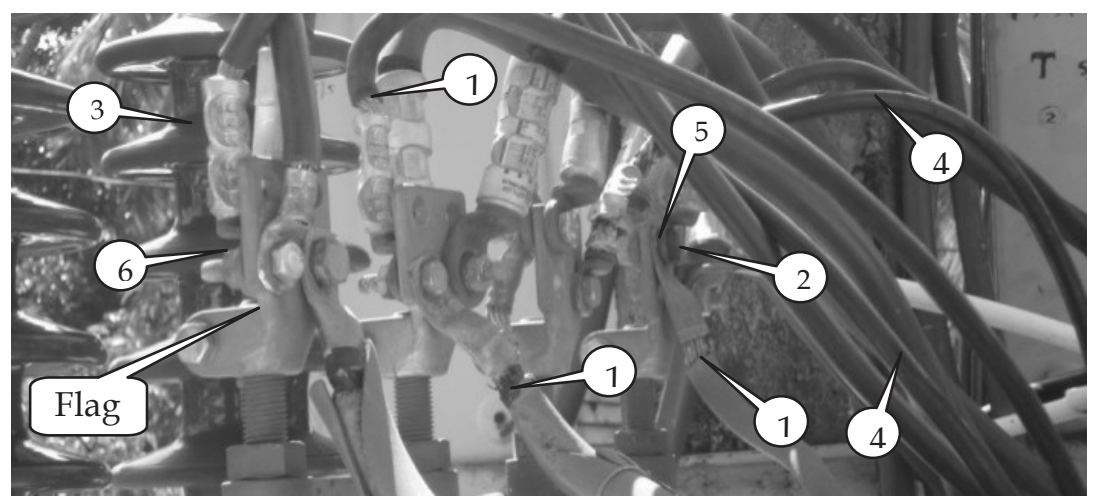

Figure 13 - Bad workman practices at transformer LV side connections Case 1

There are several connection points in the power distribution system, from the grid substation to the consumer's energy meter terminal. A lot of bad workman practices can be observed in these connection points. Unsuccessful connection practices in power distribution systems will result in loose connections and hence lesser contact areas. Some of them are discussed below. Figures 1317 indicates the reference numbers for the following bad workman practices.

1. Poor conductor preparation.

Insulation is removed more than required and the conductor strands are damaged.

2. Use of wrong connectors and materials. The bolt used for connecting the lug to the flag is corroded. This reduces the pressure on the connection and hence reducing the area of contact. Stainless steel bolts shall be used.

3. Use of wrong dies and wrong compression methods.

4. Installation of connectors so that the conductor weight is applied to the connection.

The connection should not be under tension. A guide for cables shall be fixed.

5. Connecting several connectors by using a single bolt.

This creates an additional surface for the current path of top cable and hence it will increase the connector resistance due to the presence of an additional oxide layer.

6. Not using spring washers for bolted connections.

7. Not using connectors for cable connections to equipment terminals.
Cables are tied to transformer bushing rod by few copper strands. Loose connections increase the temperature of the transformer bushing and bushing failures can be observed. Bushing failures result to oil leaks and then transformer failures.

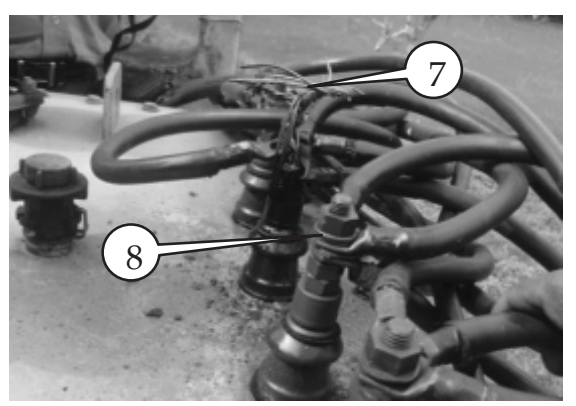

Figure 14 - Bad workman practices at transformer LV side connections - Case 2

8. Not using transformer flags for tail wire connection.

This creates an additional surface with oxide layer to current path of each cable, compared to direct flag connection. Furthermore, Current has to pass through the nut in such connections.

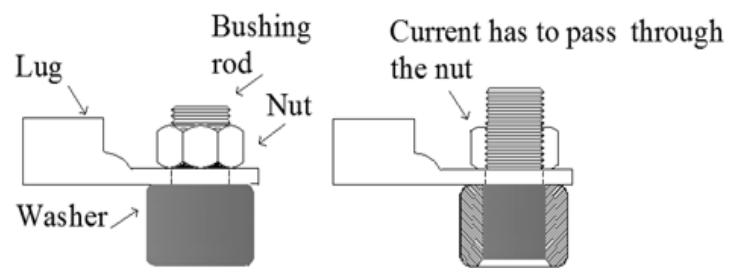

Figure 15 - Not using transformer flag.

Threads of the nut and the bushing rod are responsible for making the current path. This shows in figure 15. The 
transformer flag is shown in figure 16. Transformer flag is a pressure type connection which is designed to carry rated current. It has higher contact area to the bushing rod compared with the nut and steel bolt is fixed to apply pressure for the connection.

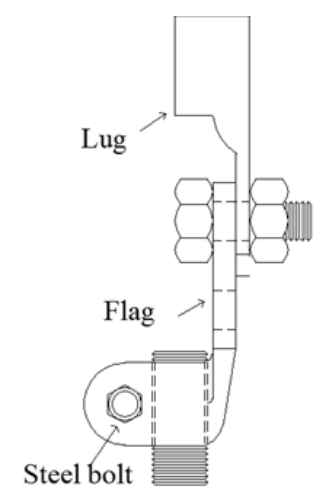

Figure 16- Transformer flag.

9. Not using connectors for cable connections to other overhead cables.

Pieces of aluminum conductors are used to connect cables to bare conductors. Properly crimped or bolted connection must be used. Binding aluminium wires doesn't apply required pressure for the connection long term and even initially.

10. Use of additional connectors for connecting two conductors.

11. Not using compression tension joints.

The Conductor itself and the wire bindings are used for making tension joints. Conductor failures will result, due to not having required strength and higher contact resistance. The Tension sleeve must be used with the proper crimp for tension joints.

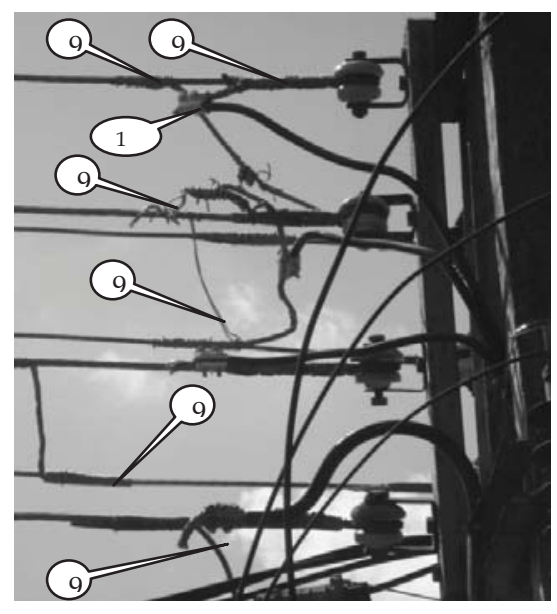

Figure 17- Bad workman practices at transformer tail wire connection to LV feeders

\section{Thermal imaging}

The principle function of an electrical connection is to satisfactorily carry the electrical current over its entire service life. The electrical load can be expected to have daily fluctuations from no load to full load and frequently to very heavy overloads. These load variations cause wide fluctuations of connections' temperatures. In addition, the ambient temperature fluctuates between daily extremes. This heat cycling causes the connections to weaken and ultimate failure of poorly designed or improperly installed connections [13], because, heat cycling causes further increasing of the contact resistance of poorly installed connectors. The temperature rise provides an important and quite convenient method of monitoring the condition of electrical connections.

Thermal imaging devices are useful in permitting a rapid scan of switchyard buses, equipment terminals and joints in power lines to detect temperature differences. Temperature differences are shown in varying shades of gray or in different colours. It must be noted that, the temperature of the connection should be less than that of the conductor for effective connection [6, 14].

Figure 18 shows Parallel grove (PG) clamps at a Gantry. Figure 18-a was taken from a digital camera. Figure 18-b shows the thermal image of the connection and surrounding objects by different colours. Blue coloured area has lower temperature compared to red coloured area. It indicates $101.8^{\circ} \mathrm{C}$ temperature at the connection in red coloured area. The connection has higher temperature compared to the conductor. The connection is a hot spot. It indicates poor connector installation. 


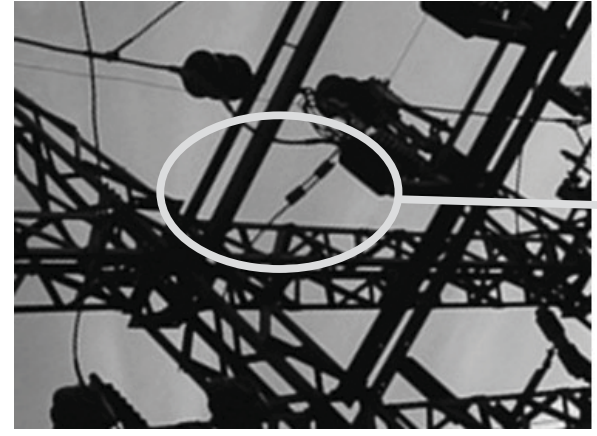

Figure 18-a

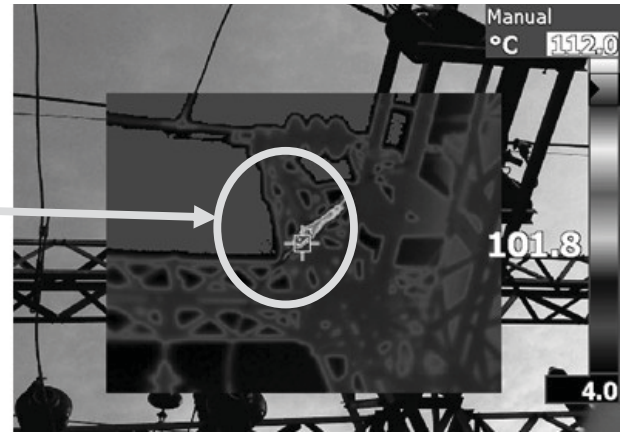

Figure 18-b

Figure 18 - Parallel grove (PG) clamps at a Gantry

\section{Discussion and Conclusions}

The study has shown that pressure connections are the most suitable type for power line connections compared with the fusion connections due to their convenience, reliability and economy in the field of making electrical connections. The main poor workman practices are none-use of connectors, use of wrong connectors, poor conductor preparation, following wrong connector installation methods and the use of wrong dies and tools..

The study has further shown that copper contacts are better compared with aluminium contacts. Silver plating of copper contacts could be done for improving the connection. A connector with an aluminium or aluminium alloy body should be used for aluminium to aluminium connections and aluminium to copper connections. The mass of aluminium should be considerably higher than copper for aluminium to copper connections. The connector should be copper for copper to copper connections. Conductor preparation, application of joint compounds and rapid connector installation with correct tools are required for making effective connections. ' $\mathrm{H}$ type compression connectors' are recommended for jumper connections and compression sleeves are recommended for tension joints. Insulated sleeves should be used for joints on $A B C$ and house service wires. Bimetallic pin connectors are recommended for energy meter terminal connections to avoid galvanic corrosion.

The standard-BS 7609:1992 is suggested for practicing in Sri Lanka, since it provides proper guideline for selection, installation and inspection of connectors in power distribution system.
The study has further shown that selection of correct die size for the connector should be based on matching of metallic areas of the connector, conductor and the die. The die for a sleeve should not be selected based only on the conductor. The area of the die should be $5 \%$ to $15 \%$ less than the total area of connector and the conductor. Connector compression should exceed the elastic limit of the material for cold flow deformation. Aluminium, Copper and Steel dies should not be interchanged and used even if the cross sectional areas are same.

Scheduling of thermal imaging surveys to detect hotspots in electrical connections and equipment is an important task for maintaining reliable power distribution system and to reduce power distribution losses. Backbone lines, primary substations and gantries are recommended to be inspected for at least every 2 to 3 years. Other medium voltage lines and substations are recommended to be inspected for at least every 3 to 4 years and this program can be extended even up to low voltage feeders. 


\section{References}

1. Troia G. D., Woo, K., \& Zahlman G., Connector Theory and Application, $4^{\text {th }}$ ed., Manchester, FCI Inc, 2007.

2. http://www.elkraft.ntnu.no,Visited,15th May 2011.

3. Rashidi, N., Soltani, S. A., \& Smatulu, R. A., "Crevice Corrosion Theory, Mechanisms and Prevention Methods", 3rd Annual GRASP Symp., Wichita State University, 2007.

4. Copper Development Association, Copper in Electrical Contacts, CDA, July, 1997.

5. http://www.compcote.com, Visited, $11^{\text {th }}$ July 2010.

6. American National Standard for Electric Connectors-Connectors for use between Aluminium to Aluminium or Aluminium to Copper Bare Overhead Conductors, ANSI standard C119.4, 2003.

7. Code of Practice for Installation and Inspection Uninsulated Compression and Mechanical Connectors for Power Cables with Copper or Aluminium Conductors, British Standard 7609, 1992.

8. Cable Lugs for Compression Connections, Ring Type for Aluminium Conductors, German Standard DIN 46 329, Technical Help to Exporters, Translation, British Standard Institution, July, 1983.

9. Cable Lugs for Compression Connections, Cover Plate Type for Copper Conductors, German Standard DIN 46 235, Technical Help to Exporters, Translation, British Standard Institution, July 1983.

10. Compression Type Tubular Terminal Ends for Aluminium Conductors of Insulated CablesSpecification, Indian Standard IS 8309, 1993.

11. Fournier, D., "Aging of Defective Electrical Joints in Underground Power Distribution Systems", in Proc., IEEE Holm Conf., Electrical Contacts, 1998, pp. 179-192.

12. http://www.geindustrial.com, Visited, $15^{\text {th }}$ June 2010
13. Timsit, R.S., \& Sprechel, J.D., “Energy Losses in Power Tap-Connectors", inProc., IEEE Int., Conf., on Transmission \& Distribution Construction, Operation $\mathcal{E} \quad$ Live-Line Maintenance, Orlando, FL, pp. 285-296, April, 1998.

14. Dang, C., \& Braunovic, M., "Metallurgic and Contact Resistance Studies of Sleeve Connectors in Aluminum Cable Splices," IEEE Trans., Compon., Hybrids, Manuf., Technol., vol. 13, pp. 74-80, March, 1990. 